
\title{
BReserch S Suare \\ Optimum Rotational and Traverse Speeds of Al-Cu Joints Welded by FSW Based on the Formability of The Joint
}

Hammed T. Elmetwally

Beni-Suef University

Hani Nagiub SaadAllah

Beni-Suef University

M.S. Abd-Elhady ( $\sim$ m.s.abdelhady@gmail.com )

Beni-Suef University

Ragab K. Abdel-Magied

Beni-Suef University

\section{Research Article}

Keywords: FSW, Dissimilar Joints, Rotational Speed, Travers Speed, Formability, Joint Strength.

Posted Date: May 18th, 2021

DOI: https://doi.org/10.21203/rs.3.rs-444307/v1

License: (9) This work is licensed under a Creative Commons Attribution 4.0 International License. Read Full License 


\section{Abstract}

Joining of aluminum to copper using Friction Stir Welding (FSW) is a primary manufacturing process that is in most applications followed by a secondary forming process. The objective of this research is to determine the optimum rotational and traverse speeds of Al-Cu Welded by FSW based on the formability of the joint. The formability and strength of Al-Cu joined by FSW are investigated under different operating conditions. Aluminum and copper blanks are welded at three different rotational speeds that are 910,1280 and $1700 \mathrm{rpm}$, under three different traverse speeds, which are 16,29 and $44 \mathrm{~mm} / \mathrm{min}$. The base metal used in this study is Aluminum (Al-1050) and copper under two conditions, i.e. as received and annealed. The mechanical properties of base metals and produced joints are evaluated by tensile and hardness tests. The Al-Cu joints by FSW are drawn into flangeless $U$ and cup shapes in order to examine the formability of the joint. The maximum tensile load, punch load and forming index were obtained when $\mathrm{Al}$ is welded to annealed $\mathrm{Cu}$ at $1700 \mathrm{rpm}$ and $16 \mathrm{~mm} / \mathrm{min}$, i.e. highest rotational and lowest traverse speeds, and that is due to the strain hardening of the joint. However, the ductility was maximum at $1280 \mathrm{rpm}$ and $44 \mathrm{~mm} / \mathrm{min}$, i.e. moderate rotational and highest traverse speed. It can be concluded that if the Al-Cu joint by FSW will be used further in a forming process, it should be welded at a moderate rotational and high traverse speed in order to avoid strain hardening and improve the ductility of the joint.

\section{Introduction}

Copper has excellent ductility, corrosion resistance, thermal and electrical conductivity, so, it is widely used to produce engineering parts such as electrical component, radiator and electronic parts. Aluminum can be used as a substitute for copper since it is similar to copper in the above-mentioned properties. Replacing copper by aluminum has potential applications since similar electric properties can be achieved at a lower price and a lower density. Aiming at replacing copper with aluminum successfully [14]. Many attempts to weld aluminum with copper are carried out by using fusion welding but defects such as low penetration, spread area in welding zone and low mechanical properties are produced [5-6]. Aluminum and copper has problem to weld together because, both metals are different in physical and mechanical properties, melting point and microstructure [7-8]. Friction stir welding (FSW) is a promising technique for welding $\mathrm{Al}$ together with $\mathrm{Cu}$, due to the good mechanical properties of the welded joint, no toxic fumes, no warping, and shielding issues, little distortion or shrinkage, and good welded joint appearance [9-12]. Friction stir welding is applied extensively in the automotive industry, especially vehicles of railway stations [13-16]. FSW is used to produce Al-Cu lap joints with excellent mechanical properties [17-18]. Other researchers used FSW technique to weld dissimilar aluminum grades or dissimilar metals butt joining with good mechanical and micro-structure properties [19-20].

The formability of welded joints from dissimilar metals [20-25] and dissimilar thicknesses [25-30] have been investigated thoroughly by many researchers, however the formability Al-Cu tailored welded blanks with friction stir welding [7-8] has been not fully investigated and understood. Abdullah et al.[27] 
investigated the formability of Al-1051 welded joint using FSW under different thicknesses. It has been concluded that there is an optimal working condition at which the highest formability is reached.

More research should be performed to determine the formability and mechanical behavior of Al-Cu joints welded by FSW under different operating conditions.

In this work, pure aluminum (Al) and copper $(\mathrm{Cu})$ are welded using FSW under different operating conditions of rotational and traverse speeds. Aluminum and copper blanks are welded at three different rotational speeds that are 910,1280 and $1700 \mathrm{rpm}$, under three different traverse speeds, which are 16, 29 and $44 \mathrm{~mm} / \mathrm{min}$. The tensile test is done for each welded joint to determine the maximum tensile load and ductility of the tested joint. The micro hardness of the upper and lower faces of the tested joints are measured. The formability of the welded joints is evaluated by drawing the specimen into U-shape and cup shape and measuring the formability load and calculating the formability index.

\section{Experimental Work}

\subsection{The Base Materials}

In this work, all specimens are prepared from pure aluminum and pure copper strips with dimensions of $160 \mathrm{~mm}$ in length, $75 \mathrm{~mm}$ in width and $2 \mathrm{~mm}$ in thickness. The mechanical properties of the material used are tested and given in Table 1. Half of the copper strips is annealed by heating the base metal $\mathrm{Cu}$ until $650^{\circ} \mathrm{C}$ and keeping it at this temperature for an hour, and then cooling it in the outside air.

Table 1. Mechanical properties of Al and Cu base metals.

\begin{tabular}{|llll|}
\hline \multicolumn{2}{|l|}{ Mechanical properties } & & \\
\cline { 1 - 3 } Vickers Hardness & Elongation & Tensile strength & Material \\
$\left(\mathrm{kg} / \mathrm{cm}^{2}\right)$ & $(\%)$ & $(\mathrm{MPa})$ & \\
\hline 27 & 25.60 & 152 & Aluminum (as received) \\
\hline 52 & 32.94 & 164 & Copper (as received) \\
\hline 45 & 44.55 & 158 & Copper (annealed) \\
\hline
\end{tabular}

\subsection{The Tool Setup}

The fixture plate with $20 \mathrm{~mm}$ thickness, $350 \mathrm{~mm}$ length and $150 \mathrm{~mm}$ in width. It has two holes with diameter of $17 \mathrm{~mm}$ to fix the fixture plate into the machine bed. Another eight holes with diameter of 10 $\mathrm{mm}$ are used to fix the $\mathrm{Al}$ and $\mathrm{Cu}$ stripes into the fixture plate. Al and $\mathrm{Cu}$ strips are tightened together using the fixture shown in Fig. 1. The welding tool is also shown in Fig. 1, and it is made from tool steel 
with $18 \mathrm{~mm}$ diameter flat shoulder. The welding tool has a tapered pin with base diameter of $3 \mathrm{~mm}$ and top diameter of $1.5 \mathrm{~mm}$ and $1.5 \mathrm{~mm}$ in height. The welding tool is fixed into the milling machine chuck.

\subsection{Working Conditions}

FSW process was proceeded using a vertical milling machine (Model: milko-35r). The tool rotational speeds are 910,1280 , and $1700 \mathrm{rpm}$, and the welding traverse speeds are 16,29 , and $44 \mathrm{~mm} / \mathrm{min}$. The tensile and the formability tests were done at a computer controlled servo-hydraulic universal testing machine (Model UH - $500 \mathrm{kN}$, Schematize ${ }^{\mathrm{TM}}$, Japan) with a cross head speed of $5 \mathrm{~mm} / \mathrm{min}$ for the tensile test and U- shape bending test, while it was $2 \mathrm{~mm} / \mathrm{min}$ for the cup-drawing forming test. The micro hardness were measured from top and bottom sides of the welding joint and linearly perpendicular to the welding direction at different positions include the stir zone (SZ), thermo mechanical affected zone (TMAZ) and heat affected zone (HAZ) of copper and aluminum sides. The micro-hardness test was carried out on Vickers testing machine (VMH tester model number 1600-4981).

\subsection{Formability Test}

The formability test is based on two tests, which are; (1) bending and (2) deep drawing of a cup. The bending test is performed based on the setup shown in Fig. 2.a, and it consists of fixed jaws, i.e. the die, and a punch. The punch is $50 \mathrm{~mm}$ wide, $150 \mathrm{~mm}$ long and $10 \mathrm{~mm}$ thick. The distance between the fixed jaws is $56 \mathrm{~mm}$. The tested joint, i.e. the Al-Cu joint welded by FSW, is mounted over the fixed jaws and the punch presses over the joint to perform a $U$ shape, as shown in Fig. 2.c. The die and punch used in the deep drawing test are shown in Fig. 2.b. The drawing process is performed with aid of lubricant. The diameter of the punch is $72 \mathrm{~mm}$, while the diameter of the die is $76 \mathrm{~mm}$. The blank diameter $D$ is calculated based on the following formula [27],

$$
\mathrm{D}=\sqrt{d^{2}+d * h}
$$

where $\mathrm{d}$ is the punch diameter and $\mathrm{h}$ is the cup height. The shape and dimensions of the cup produced during the deep drawing test are shown in Fig. 2.d. In both tests, i.e. the deep drawing test and the bending test, the punch is operated by the universal testing machine, Model UH - $500 \mathrm{kN}$, Schematize ${ }^{\mathrm{TM}}$, Japan. The deep drawing tests were done on the Al-Cu welded joints that have the highest and lowest tensile strength for the sake of comparison, also, in case of annealed and non-annealed copper.

\section{Results And Discussion}

\subsection{Tensile Strength and Elongation}

The tensile strength and elongation \% of the welded Al-Cu joints are presented in Fig. 3 in case of nonannealed copper and in Fig. 4 in case of annealed copper. The tensile strength and the elongation \% are presented versus the traverse speed and as a function of the rotation speed. It can be seen from Figs. 3.a and 4 .a that, as the traverse speed increases or the rotational speed decreases the strength of the joint 
decreases, and vise versa, which is in line with previous literature [8-12]. Increasing the traverse speed, i.e. the welding speed, decreases the contact time between the tool and the workpeice, which decrease the energy input to the workpiece and consequently heating of the joint [30]. Decreasing the energy input to the joint i.e. heating of the joint, by increasing the traverse speed, decreases the strength of the joint. Also, decreasing the rotational speed decreases the heating of the joint which affects the strength of the joint. However, it can be seen from Figs. 3.b and 4.b. that as the traverse speed increases the elongation \% increases, such that it can be concluded that the influence of increasing the traverse speed on the ductility of the joint is opposite to its effect on the tensile strength. This behavior can be attributed to the decrease in heat generation with the increase of the traverse speed or decrease of the rotational speed. Overheating of the welding joint improves the welding strength but on the other hand causes strain hardening, which affects the ductility of the joint. It can also be concluded from Fig. 3 that at the moderate traverse speed $29 \mathrm{~mm} / \mathrm{min}$ the elongation \% is almost the same value for all rotational speeds, and the variation in the tensile strength is almost negligible, which indicates that the elongation $\%$ is dependent on the ultimate tensile strength such that if the ultimate tensile strength remains constant, irrespective of the welding conditions, the elongation percentage remains also constant.

The joint efficiency is obtained as the ratio between the ultimate tensile strength of Al-Cu joint to the ultimate tensile strength of Al base metal (the weaker part of the joint). The maximum efficiency of the Alannealed $\mathrm{Cu}$ joint is $78.6 \%$ at $1700 \mathrm{rpm}$ and $16 \mathrm{~mm} / \mathrm{min}$, i.e. at the highest rotational speed and the lowest Travers speed, while the minimum efficiency is $36.5 \%$ at $910 \mathrm{rpm} / 44 \mathrm{~mm} / \mathrm{min}$ the lowest rotation speed and highest Travers speed. The maximum tensile strength specimen is $83.6 \%$ at $1280 \mathrm{rpm}-16$ $\mathrm{mm} / \mathrm{min}$, which is not the highest rotational speed, while the minimum value is $29.6 \%$ at $910 \mathrm{rpm} / 44$ $\mathrm{mm} / \mathrm{min}$. is the lowest rotational speed and highest Travers speed. It can be concluded based on Figs. 3 and 4 and the joint efficiency that if the function of the joint is stress resistance then the rotational speed should be maximum and the traverse speed should be minimum to enhance the joint strength, but if the welded joint will be used further in a forming process, then high rotational speeds with low traverse speeds should be avoided.

\subsection{Formability of Al-Cu Joints Welded by FSW}

Most of the welding processes are considered as primary process that should be followed by a secondary process. In many applications, the secondary process is one of the forming methods so, the investigation of the formability of Al-Cu joints welded by FSW is so important for the applicability of the welding process. The formability investigation will include: calculation of the forming index based on the tensile test data, determining the bending strength from free bending U-shape test, and finally obtaining the maximum load and studying the fractures that are produced during formability cup-shape test.

\subsubsection{Formability index of Al-Cu joints welded by FSW}

The formability index can be calculated theoretically based on the following equation [26],

Formability Index = Ultimate tensile strength (MPa)×Elongation (\%) (2) 
The formability index is a measure of the formability forces required for a forming process. The formability index is calculated for the welded joints at different traverse speeds in case of annealed and non-annealed copper, and the results are presented in Fig. 5. However, only the extreme rotational speeds, i.e. the highest and the lowest rotational speeds, are presented in order to clarify the influence of the rotational speed on the formability index. It can be seen from Fig. 5 that the formability index in case of a higher rotational speed, i.e. $1700 \mathrm{rpm}$, is higher than in case of a lower rotational speed, i.e. $910 \mathrm{rpm}$, and that is due to the high joint strength in case of $1700 \mathrm{rpm}$ than in case of $910 \mathrm{rpm}$. Increasing the traverse speed decreases the formability index and that is due to the decrease in the strength of the welded joint with the traverse speed, and such a conclusion is clearly illustrated in Fig. 5. Increasing the rotational speed or decreasing the traverse speed increases the amount of heat energy added to the joint, which improves the adhesion and the tensile strength of the joint, consequently increases the formability index of the joint, and vice versa. This concludes that FSW joints with large formability index should not be used in forming applications, because it requires large forming forces as well as a lot of energy will be used, which can destroy the feasibility of the forming process, and this conclusion is illustrated in the bending tests that is presented in the next section.

\subsubsection{Bending test results}

Bending tests were done for the Al-Cu joints welded at the different rotational speeds examined in this work, i.e. $1700 \mathrm{rpm}, 1280 \mathrm{rpm}$ and $910 \mathrm{rpm}$, while the traverse speed was kept constant at $16 \mathrm{~mm} / \mathrm{min}$. The bending load-displacement curves of the performed tests are presented in Fig. 6 . It has to be mentioned that the joint welded at a rotational speed of $910 \mathrm{rpm}$ and a traverse speed of $16 \mathrm{~mm} / \mathrm{min}$ fractured and cracked during the bending test, such that it was not possible to continue the test and present the results. The punch load increases as the punch travels downwards into the welded blank to form the U-shape until reaching a maximum value, then the load gradually decreases until it reaches a minimum value and stabilizes, and at that point the forming process has been completed. It can be seen that the maximum bending force in case of the joint welded at a rotational speed of $1700 \mathrm{rpm}$ is $260 \mathrm{kgf}$ while in case of the $1280 \mathrm{rpm}$ joint is $150 \mathrm{kgf}$. The maximum bending force in case of $1700 \mathrm{rpm}$ joint is about 1.7 times more than the $1280 \mathrm{rpm}$ joint, and that is due to difference in the joint strength. Images of Al-Cu joints after the bending test are presented in Fig. 7. The joint welded at a rotational speed of $1700 \mathrm{rpm}$ has endured the bending test, while the joint welded at a rotational speed of $910 \mathrm{rpm}$ failed the test and was broken. An important conclusion can be drawn from the results presented in Fig. 6 is that the energy required for forming the $1700 \mathrm{rpm}$ joint is higher than that of the $1280 \mathrm{rpm}$ joint. The forming energy is calculated based on the following,

Forming Energy $=\int_{0}^{x} F d x$

Where $\mathrm{F}$ is the forming force, i.e. the punch load, and $\mathrm{x}$ is the punch displacement. By carrying the above integral over the force - displacement curve presented in Fig. 6 will result in the area under the curve. The forming energy in case of the $1700 \mathrm{rpm}$ joint is $41.07 \mathrm{~kJ}$, while in case of the $1280 \mathrm{rpm}$ joint is $12.56 \mathrm{~kJ}$. The forming energy in case of the $1700 \mathrm{rpm}$ joint is about 3.3 times larger than in case of the $1280 \mathrm{rpm}$ 
joint, which indicates that the energy bill will be at least 3.3 times larger. It can be concluded that using large rotational speeds together with low traverse speeds in FSW will result in a very strong joints that can affect the feasibility of the joint if it will be used further in a forming process. On the other hand, using low rotational speeds and high traverse speeds in FSW can result in a weak joint that can be easily broken during a forming process.

\subsubsection{Cup test results}

The results of the punch force-displacement curves during the deep drawing of Al-Cu welded joints are plotted in Fig. 8. The Al-Cu joint is welded at rotational speeds of $1700 \mathrm{rpm}$ and $1280 \mathrm{rpm}$, while the traverse speed was constant at $16 \mathrm{~mm} / \mathrm{min}$. During the cup-forming test, the load increases as the punch starts to form the cup until the blank passes throw the die then the load decreases, as can be seen in Fig. 8. It has to be mentioned that the joint welded at a rotational speed of $910 \mathrm{rpm}$ and a traverse speed of $16 \mathrm{~mm} / \mathrm{min}$ fractured during the cup test. It can be concluded by comparing the loads in the cup test to the bending test, that the loads in the cup test are higher than the loads in the bending test. In the bending test the stresses are uniaxial, i.e. in the direction parallel to the welding line as indicated in Fig. 9, while in the cup test, the stresses are biaxial, i.e. in the welding direction and normal to the welding direction, which resists the punch motion and increases the punch load. The welding direction is called the $x$ direction in Fig. 9, while the direction perpendicular the welding direction will be called the y-direction. The work done to withdraw the Al-Cu joint welded at a speed of $1700 \mathrm{rpm}$ is $36 \mathrm{~kJ}$, while in case of the 1280 rpm joint is $23.6 \mathrm{~kJ}$, as indicated in Fig. 8. The forming energy in case of withdrawing the Al-Cu joint into a cup is calculated based on Eq. (3), which is the area under the load-displacement curve. The forming energy in case of the $1700 \mathrm{rpm}$ joint is about 1.52 times larger than in case of the $1280 \mathrm{rpm}$ joint, which is in line with the previous conclusion of the bending test, i.e. more forming energy is required for the joints that are welded at large rotational speeds together with low traverse speeds due to the strain hardening that occurs during the welding process.

Images of the welded Al-Cu joint after the cup test are shown in Fig. 10, and that is in the case of welding at rotational speeds of (a) $1700 \mathrm{rpm}$ and (b) $910 \mathrm{rpm}$, while the traverse speed is equal to $16 \mathrm{~mm} / \mathrm{min}$, and the copper has been annealed. It can be seen that the breakage of the Al-Cu joint welded at a rotational speed of $910 \mathrm{rpm}$ occurred at the welding line, which is the weakest point in the joint, and a detailed image of the fracture is shown in Fig. 11. Welding at low rotational speeds lowers the heat energy added to the joint, consequently, decreases the amount of aluminum melts that has been transferred from the aluminum side to the copper side. The amount of aluminum melts determine the strength of the welded joint. Increasing the welding rotational speed increases the amount of aluminum melts, and consequently improves the strength of the welded joint. It can be concluded from Fig. 11 that the failure of the joint occurred in the aluminum covering the joint and the fracture is mainly a cup and cone failure, i.e. a ductile failure under tensile stresses. The lower surface of the joint is subjected to compression stresses due to the applied punch load, while the upper surface of the joint is mainly aluminum and subjected to tensile stresses during the cup test, and due to these tensile stresses failure occurs in the aluminum in the shape of a cup and cone. 


\subsection{Micro Hardness Results}

In the present study the micro-hardness of the top and bottom surfaces of the welded joints are mesaured as a function of the distance from the welding line, and perpendicular to the welding line. The microhardness distribution at (a) the top and (b) the bottom surface of the Al-Cu joint are presented in Fig. 12 . The Al-Cu joint is welded at rotational speeds of $1700 \mathrm{rpm}$ and $1280 \mathrm{rpm}$, while the traverse speed was constant at $16 \mathrm{~mm} / \mathrm{min}$, and the copper has been annealed. The base hardness of the Aluminum strip is $27 \mathrm{~kg} / \mathrm{cm}^{2}$, while of the annealed copper strip is $45 \mathrm{~kg} / \mathrm{cm}^{2}$ based on Vickers micro-hardness test.

The maximum Vickers hardness in the stir zone (SZ) and at the top surface of the welded joint is 85 $\mathrm{kg} / \mathrm{cm}^{2}$, while at the bottom surface of the joint is $59 \mathrm{~kg} / \mathrm{cm}^{2}$, and that is in the case of welding at a rotational speed of $1700 \mathrm{rpm}$. The stir zone is $10 \mathrm{~mm}$ left and right to the welding line as indicted in Fig. 12, and it is dependent on the FSW tool diameter, which is in this case is equal to $18 \mathrm{~mm}$. It can be concluded from Fig. 12 that the micro-hardness in the SZ and at the top surface of the welded joint, i.e. the surface facing the FSW tool, is greater than that at the bottom surface, and that is due to the more strain hardening that occurred in the top surface than at the bottom surface. The top surface of the welded joint is subjected to more friction and heating than the bottom surface due to the stirring effect of the welding tool, consequently, more strain hardening at the top than the bottom.

The maximum Vickers hardness at the top surface of the welded joint at a rotational speed of $1700 \mathrm{rpm}$ is $85 \mathrm{~kg} / \mathrm{cm}^{2}$, while at a rotational speed of $1280 \mathrm{rpm}$ is $75 \mathrm{~kg} / \mathrm{cm}^{2}$, which indicates that as the rotational speed increases the hardness increases. Increasing the rotational speed of the welding tool increases the heating of the welded joint, consequently, more strain hardening.

\section{Conclusions}

Pure aluminum is welded to pure copper by friction stir welding (FSW), in case of the copper being annealed or not annealed. The welding process is performed under different rotational and welding speeds. The objective of this research is to determine the optimum rotational and traverse speeds of AlCu Welded by FSW based on the formability of the joint, and the following conclusions are drawn:

1. Overheating of the welding joint improves the welding strength but on the other hand causes strain hardening, which affects the ductility of the joint.

2. Increasing the rotational speed of the FSW tool increases the hardness of the welded joint.

3. More forming energy is required for the joints that are welded at large rotational speeds together with low traverse speeds due to the strain hardening that occurs during the welding process.

4. The influence of increasing the traverse speed on the ductility of the joint is opposite to its effect on the tensile strength.

5. The elongation\% of the welded joint is dependent on the ultimate tensile strength such that if the ultimate tensile strength remains constant, irrespective of the welding conditions, the elongation percentage remains also constant. 
6. Increasing the rotational speed or decreasing the traverse speed increases the amount of heat energy added to the joint, which improves the adhesion and the tensile strength of the joint, consequently increases the formability index of the joint, and vice versa.

7. If the function of the joint is stress resistance then the rotational speed should be maximum and the traverse speed should be minimum to enhance the joint strength, but if the welded joint will be used further in a forming process, then high rotational speeds with low traverse speeds should be avoided.

\section{Declarations}

\section{Compliance with Ethical Standards}

The authors declare that the paper is written in "Compliance with Ethical Standards" of the journal.

The manuscript is not be submitted to more than one journal for simultaneous consideration.

The submitted work is original and have not been published elsewhere in any form or language (partially or in full)

The results are presented clearly, honestly, and without fabrication, falsification or inappropriate data manipulation (including image based manipulation).

No data, text, or theories by others are presented as if they were the author's own.

\section{Consent to Participate}

I really don't understand this point.

\section{Consent to Publish}

On behalf of all authors, me, Prof.Dr. M.S. Abd-Elhady, the corresponding author, grant the Publisher an exclusive licence to publish the article if it is accepted as well as that we transfer the copyright of the article to the Publisher, when it is accepted by the journal.

\section{Authors Contributions}

$1^{\text {st }}$ author: Hammed T. Elmetwally

Preparation of the experiments working plan, analysis and discussion of results, writing of the manuscript.

$2^{\text {nd }}$ author: Hani N. SaadAllah

Preparation of the experiments, performing the experiments, analysis and discussion of results, writing of the manuscript. 
$3^{\text {rd }}$ author: M.S. Abd-Elhady

Analysis and discussion of results, revision of the paper.

$4^{\text {th }}$ author: Ragab K. Abdel-Magied.

Revision of the paper.

\section{Funding}

The authors did not receive support from any organization for the submitted work, and no funds, grants, or other support was received.

\section{Competing Interests}

The authors have no conflicts of interest to declare that are relevant to the content of this article.

All authors certify that they have no affiliations with or involvement in any organization or entity with any financial interest or non-financial interest in the subject matter or materials discussed in this manuscript.

\section{Availability of data and materials}

All presented data are available under any request.

\section{Code availability}

Not applicable.

\section{References}

1. Kahl, S. and Osikowicz, W. "Composite Aluminum-Copper Sheet Material by Friction Stir Welding and Cold Rolling" Journal of Materials Engineering and Performance, 2013, vol. 22(8), pp. 2176-84 .

2. Muthu, M.F.X., Jayabalan, V. "Tool travel speed effects on the microstructure of friction stir welded aluminum-copper joints" Journal of Material Processing Technology, 2015, vol. 217, pp. 105-113.

3. Yue, Y., Wang, G., Yang, k., Wu, B., Yan, D. "Friction stir butt welding thin Aluminum alloy sheets" The International journal of Advanced Manufacturing technology, 2018, vol. 96, pp.139-3147.

4. Liu, Z., Ji, S., Meng, X. "Joining of magesium and aluminum alloys viaultrasonic assisted friction stir welding at low temperature" The International Journal of Advanced Manufacturing technology, 2018, vol. 97, pp. 4127-4136.

5. Kah, P., Vimalraj, C., Martikainen, J., Suoranta, R. “Factors Influencing Al-Cu Weld Properties by Intermetallic Compound Formation" International Journal of Mechanical and Materials Engineering, 2015, vol. 10(1), pp. 1-13. 
6. Feng, J.I., Song-bai, X., Ji-yuan, L., Yin-bin, L., Shui-qing, W. “Microstructure and properties of Cu/Al joints brazed with Zn-Al filler metals" Transactions of Nonferrous Metals Society of China, 2012, vol. 22(2), pp. 281-287.

7. Celik, S., and Cakir, R. "Effect of Friction Stir Welding Parameters on the Mechanical and Microstructure Properties of the Al-Cu Butt Joint" Metals, 2016, vol. 6, pp.133-148.

8. Tan, C.W., Jiang, Z.G., Li, L.Q., Chen, Y.B., Chen, X.Y. "Microstructural Evolution and Mechanical Properties of Dissimilar Al-Cu Joints Produced by Friction Stir Welding" Materials \& design, 2013, 51, pp. 466-473.

9. Xue, P., Xiao, B.L., Ni, D.R., Ma, Z.Y. “Enhanced mechanical properties of friction stir welded dissimilar Al-Cu joint by intermetallic compounds" Materials Science and Engineering: A, 2010, vol. 527, pp. 5723-5727.

10. Xue, P., Ni, D.R., Wang, D., Xiao, B.L., Ma, Z.Y. “Effect of friction stir welding parameters on the microstructure and mechanical properties of the dissimilar Al-Cu joints", Materials Science and Engineering: A, 2011, vol. 528, pp. 4683-4689.

11. Carlone, P., Astarita, A., Palazzo, G.S., Paradiso V., Squillace, A. "Microstructural aspects in Al-Cu dissimilar joining by FSW" The International Journal of advanced Manufacturing technology, 2015, vol. 79, pp.1109-1116.

12. Sun, Y., He, D., Xue, F., Lai, R. "Effect of Tool Rotational Speeds on the Microstructure and Mechanical Properties of a Dissimilar Friction-Stir-Welded CuCrZr/CuNiCrSi Butt Joint" Metals, 2018 , vol. 8, pp. 526.

13. Beygi, , Kazeminezhad, M., Mehrizi, M.Z., Eisaabadi, G.B., Loureiro, A. "Friction stir butt welding Of AlCu bilayer laminated composites: analysis of force, torque and temperature" The International journal ofAdvanced Manufacturing technology, 2017, vol. 88, pp.393-400.

14. Mubiayi, M.P., Akinlabi, E.T. "Friction Stir Welding of Dissimilar Materials between Aluminum Alloys and Copper-An Overview" In Proceedings of the World Congress on Engineering, 2013, vol. 3, London, UK, 3-5.

15. Galvao, I., Leal, R.M., Lourierio, A., Rodrigues, D.M. “Material flow in heterogeneous friction stir welding of aluminum and copper thin sheets" J. Science and Technology of Welding \& Joining, 2010, vol. 15 ,pp. 654-660.

16. Galvao, I., Oliveira, J.C., Lourierio, A., Rodrigues, D. "Formation and distribution of brittle structures in friction stir welding of aluminum and copper: Influence of process parameters" Science and Technology of Weldingand Joining, 2011, vol. 16, pp. 681-689.

17. Bisadi, H., Tavakoli, A., Sangsaraki, M.T., Sangsaraki, K.T. "The influences of rotational and welding speeds on microstructures and mechanical properties of friction stir welded Al5083 and commercially pure copper sheets lap joints" Materials \& Design, 2013, vol. 43, pp. 80-88.

18. Akbari, M., Behemmat, P., Panahi, H.M., Givi K.B.M. “Enhancing metallurgical and mechanical properties of friction stir lap welding of Al-Cu using intermediate layer" Science and Technology of Welding \& Joining, 2013, vol. 18, pp. 518-524. 
19. Akinlabi, E.T., Els-Botes, A., McGrath, P.J. “Effect of travel speed on joint properties of dissimilar metal friction stir welds" Proceedings of 2nd International Conference on Advances in Engineering and Technology(AET). Uganda, 2011, pp. 155-161.

20. Li, X.W., Zhang, D.T., Cheng, Q.I.U., Zhang, W. "Microstructure and mechanical properties of dissimilar pure copper/1350 aluminum alloy butt joints by friction stir welding" Transactions of Nonferrous Metals Society of China, 2012, vol. 22(6), pp.1298-1306.

21. Leitão, C., Emílio, B., Chaparro, B.M., Rodrigues, D.M. "Formability of similar and dissimilar friction stir welded AA 5182-H111 and AA 6016-T4 tailored blanks", Materials and Design, 2009, vol. 30, pp. 3235-3242.

22. Garware, M., Kridli, G.T., Mallick, P.K. "Tensile and fatigue behavior of friction-stir welded tailor-welded blank of aluminum alloy 5754", Journal of Materials Engineering and Performance, 2010, vol. 19(8), pp. 1161-1171.

23. Mishra, R.S., Ma, Z.Y. "Friction stir welding and processing", Mater Sci Eng, 2005, vol. 50(1-2), pp. 178.

24. Cheng, C.H., Chan, L.C., Chow, C.L. "Weldment properties evaluation and formability study of tailorwelded blanks of different thickness combinations and welding orientations", Journal of Materials Science, 2007, vol. 42, pp. 5982-5990.

25. Panda, S.K., Kumar, D.R., "Improvement in formability of tailor welded blanks by application of counter pressure in biaxial stretch forming", J Mater Process Technol, 2008, vol. 204, pp. 70-79.

26. Kolahgar, S., Ghaffarpour, M., Habibi, N., Kokabi, A. H., and Akbarzadeh, A. “Formability of friction stir-welded blanks with different thickness ratios", Metallurgical and Materials Transactions A, 2016, vol. 47, pp. 2177-2187.

27. Abdullah, M., Abdel-Magied, R.K., Elsheikh, M.N. "Experimental investigation of formability of Al-1050 tailor- welded blanks", The International Journal of Advanced Manufacturing Technology, 2017, vol. 89 , pp. 791-801.

28. Panda, S.K., Kumar, D.R. "Improvement in formability of tailor welded blanks by application of counter pressure in biaxial stretch forming", Journal of Materials Processing Technology, 2008, vol. 204, pp. 70-79.

29. M., Safdarian, R., Santos, A.D., Loureiro, A., Vilaca, P., Jorge, R.N. "Study on the formability of aluminum tailor welded blanks produced by friction stir welding ",The International Journal of Advanced Manufacturing Technology, 2016, vol. 83(9-12), pp. 2129-2141.

30. Elmetwally, H.T., SaadAllah, H.N., Abd-Elhady, M.S., Abdel-Magied, R.K. "Optimum combination of rotational and welding speeds for welding of Al/Cu-butt joint by friction stir welding ", The International Journal of Advanced Manufacturing Technology, 2020, vol. 110, pp. 163-175.

\section{Figures}






(a)

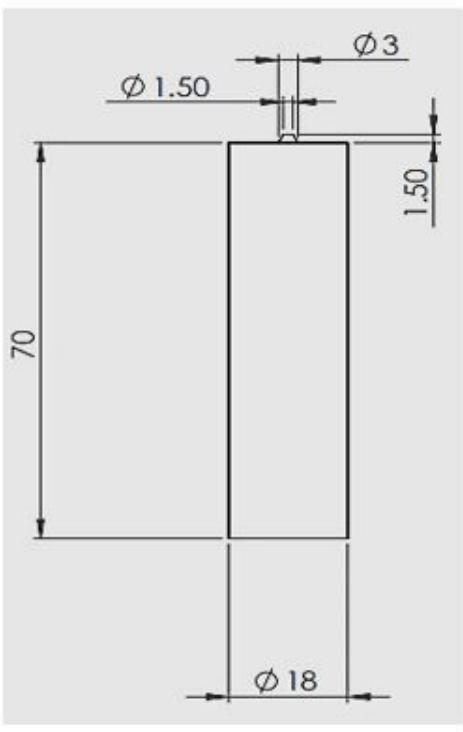

(b)

\section{Figure 1}

The welding setup used in the performed experiments (a) and the welding tool (b). All dimensions are in mms. 


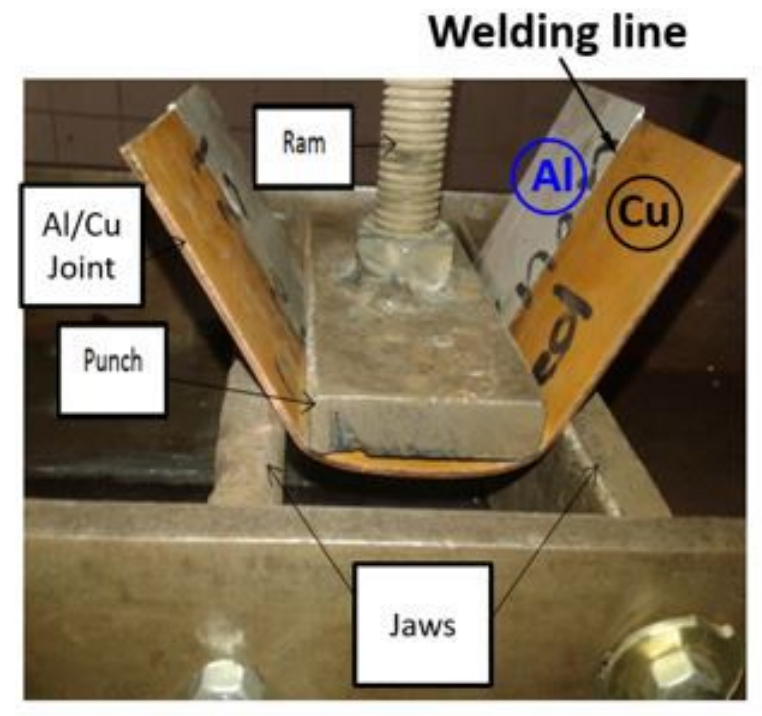

(a)

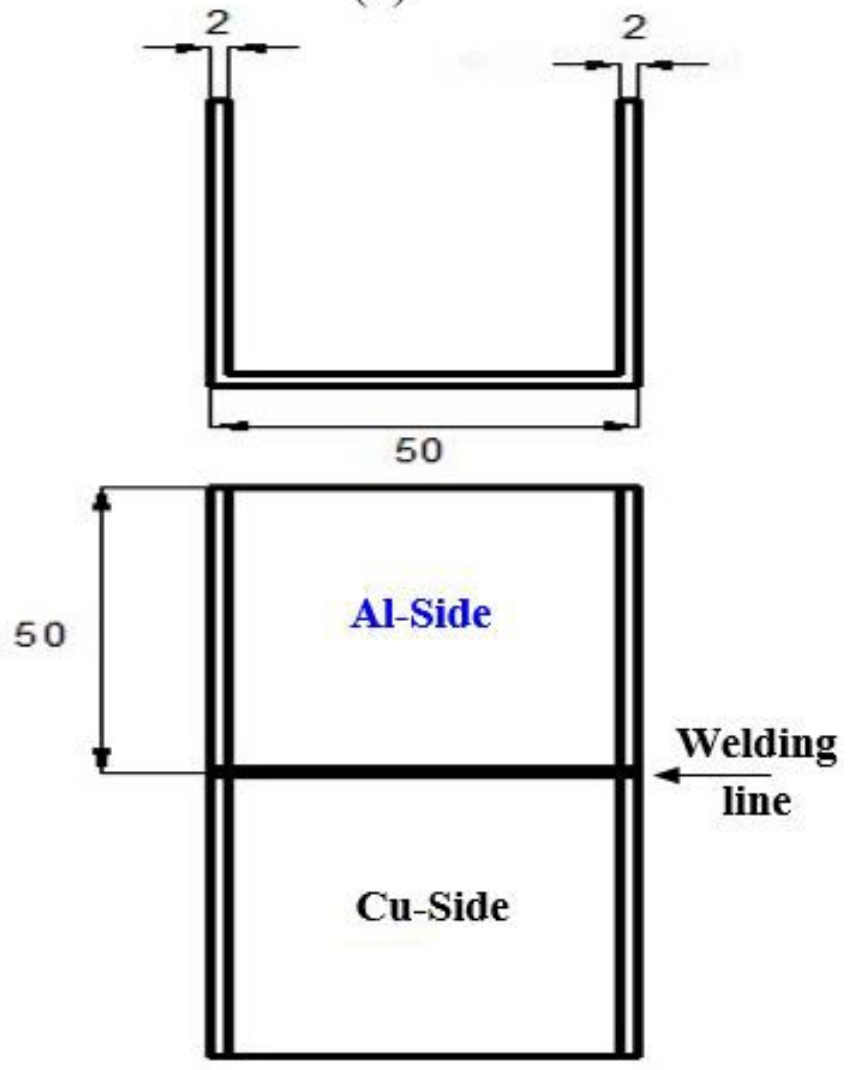

(c)

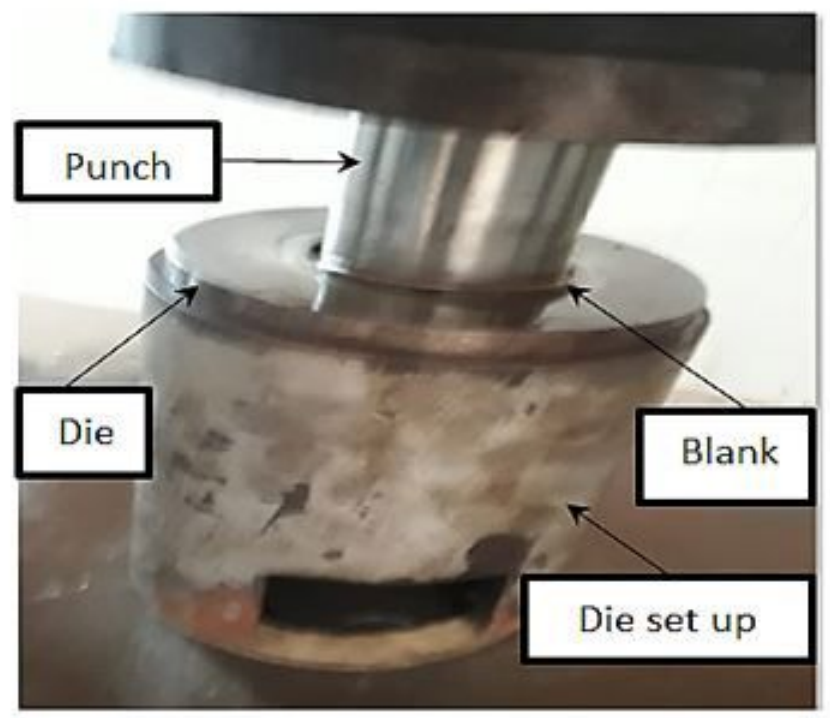

(b)

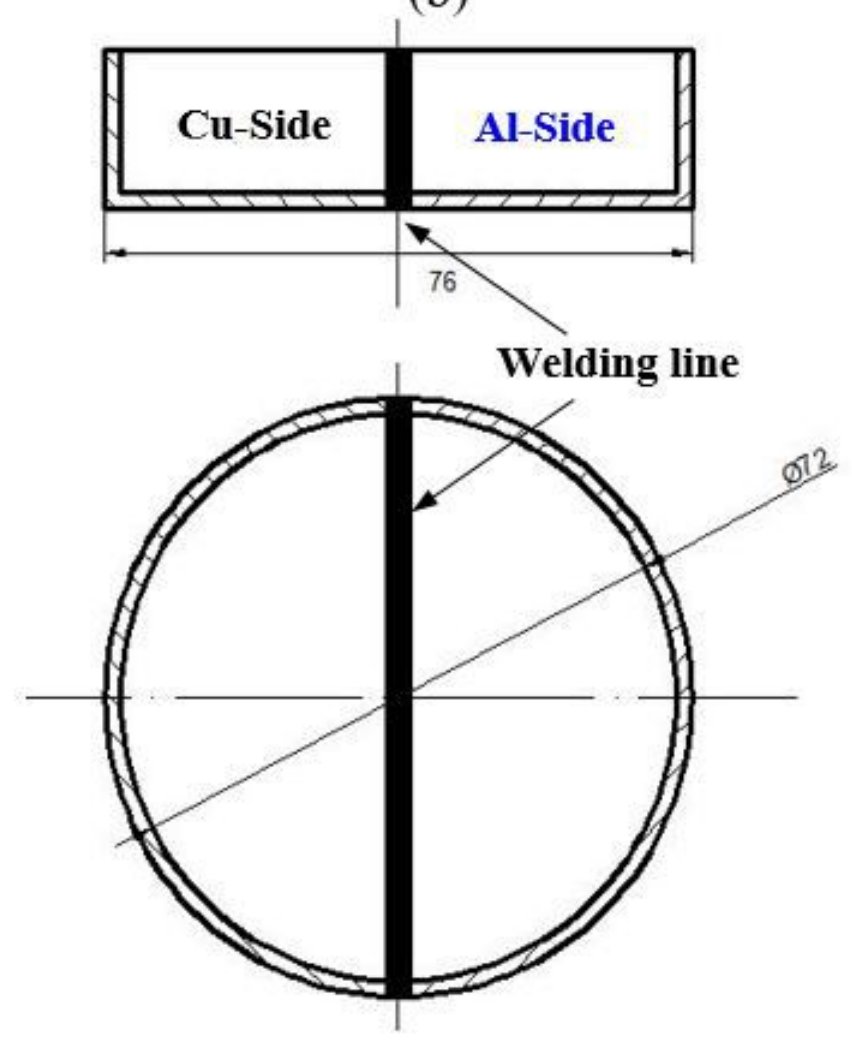

(d)

Figure 2

The punch and die used in the bending test and the deep drawing of a cup are shown in (a) and (b), while the corresponding products are shown in (c) and (d), respectively. All dimension are in mms. 


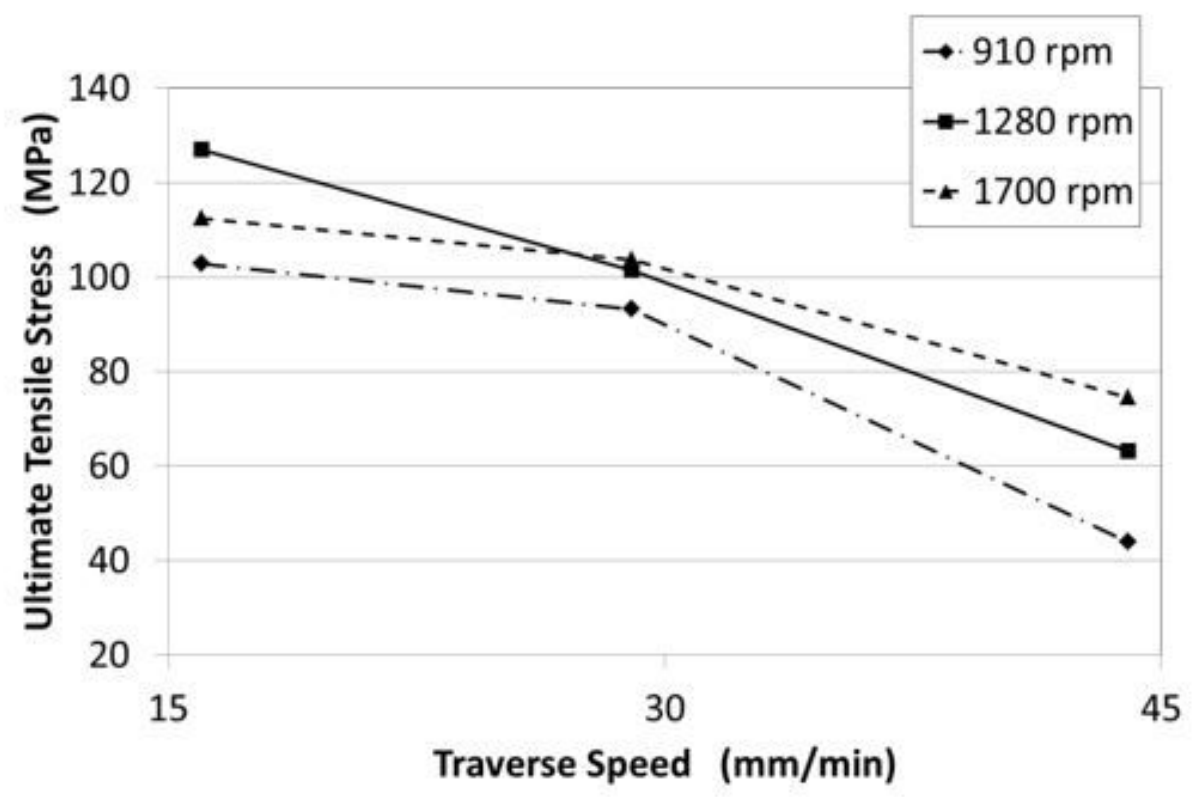

(a)

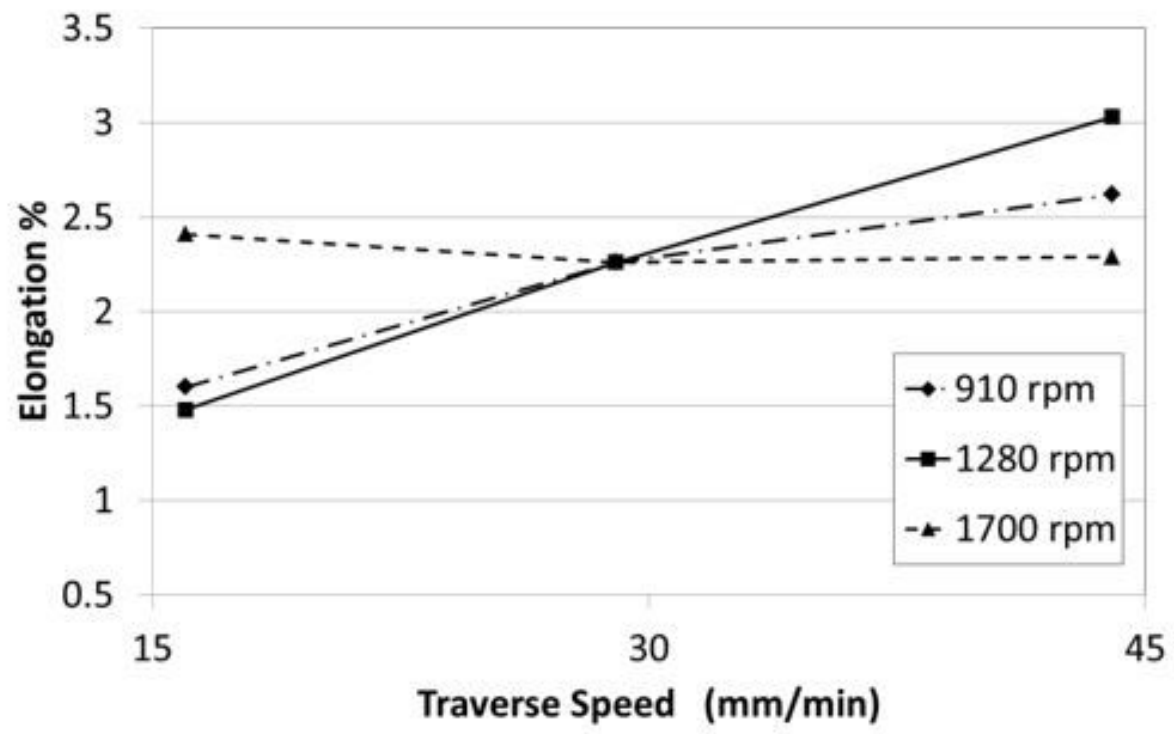

(b)

\section{Figure 3}

Tensile strength (a) and elongation \% (b) of the welded Al-Cu joint, versus the welding Traverse speed and as a function of the rotational speed, i.e. 910, 1280 and 1700 r.p.m. The copper in this case is nonannealed. 


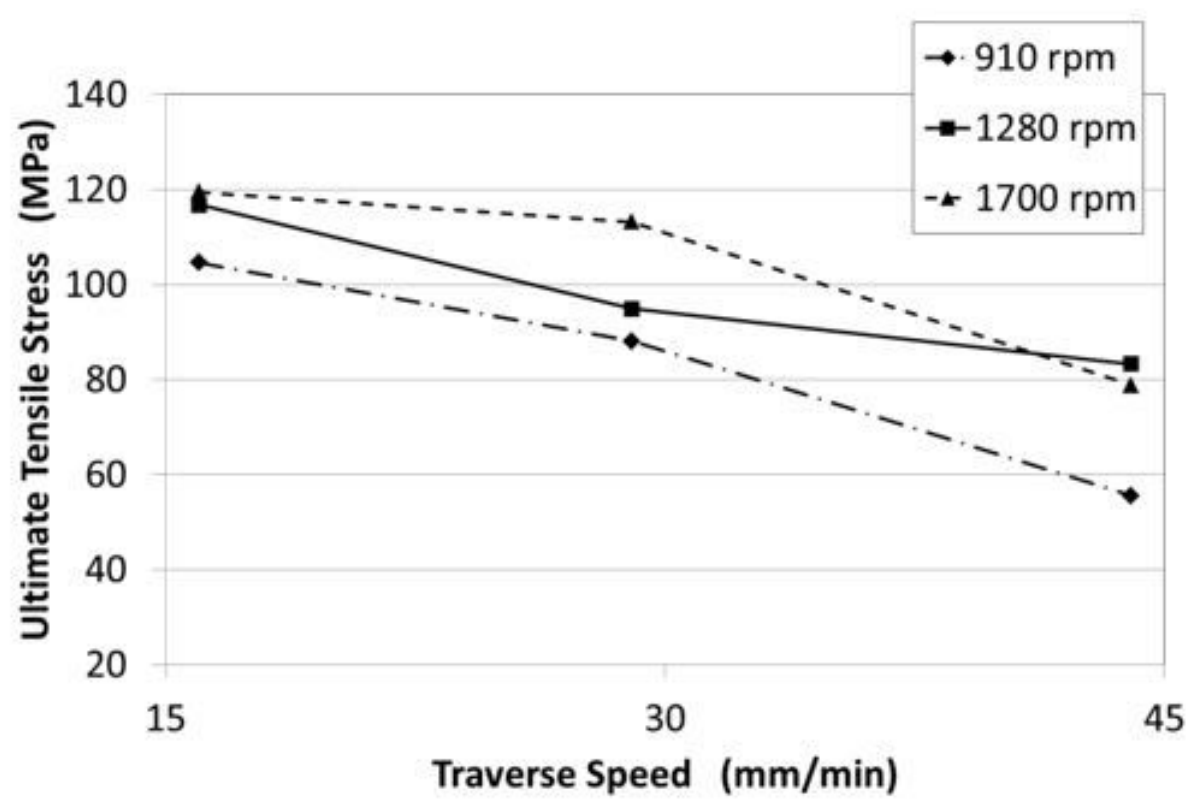

(a)

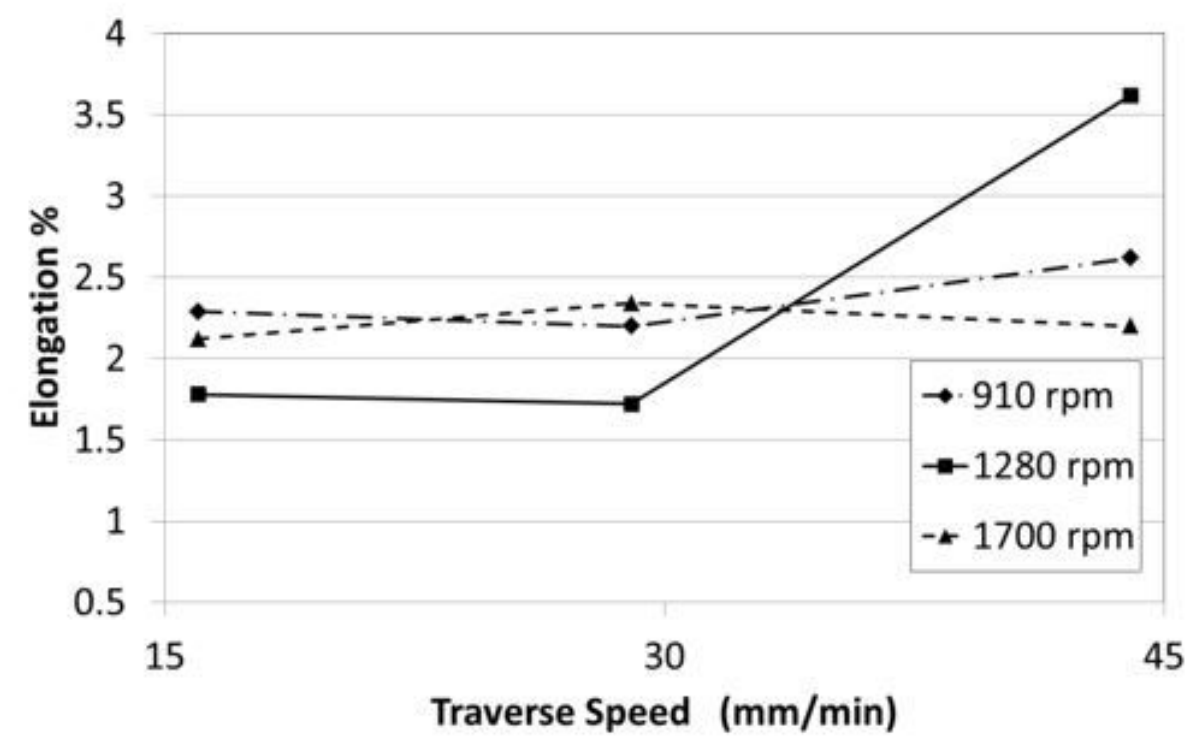

(b)

\section{Figure 4}

Tensile strength (a) and elongation \% (b) of the welded Al-Cu joint, versus the welding Traverse speed and as a function of the rotational speed, i.e. 910,1280 and 1700 r.p.m. The copper in this case is annealed. 


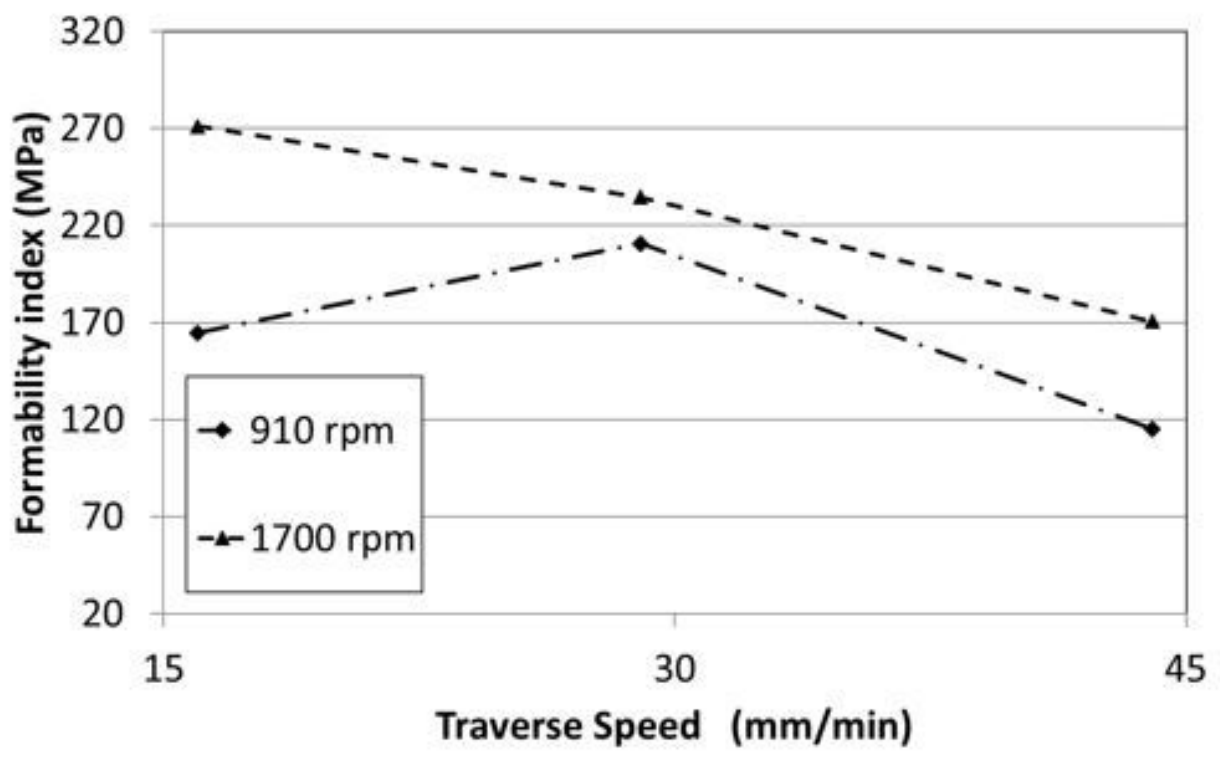

(a)

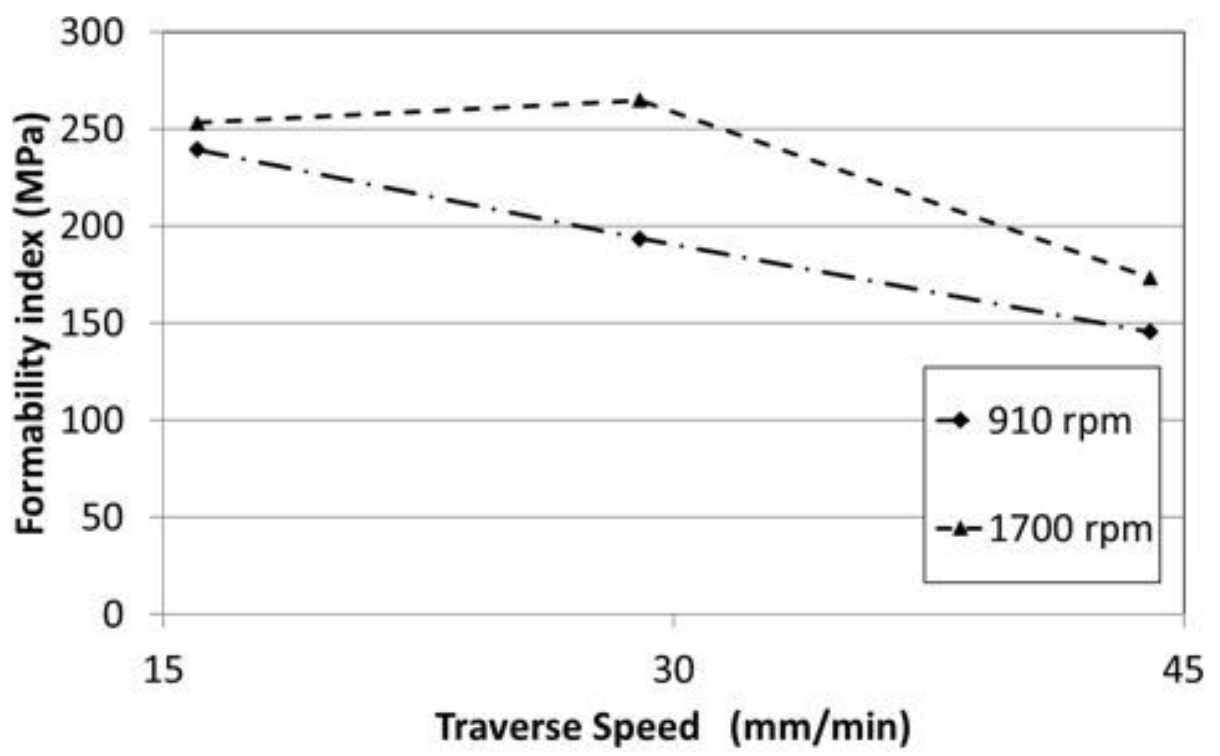

(b)

\section{Figure 5}

Formability index of the welded Al-Cu joint by FSW as a function of the welding traverse speed, in case of (a) non-annealed copper and (b) annealed copper. The rotational speed is varied between $910 \mathrm{rpm}$ and 1700 rpm. 


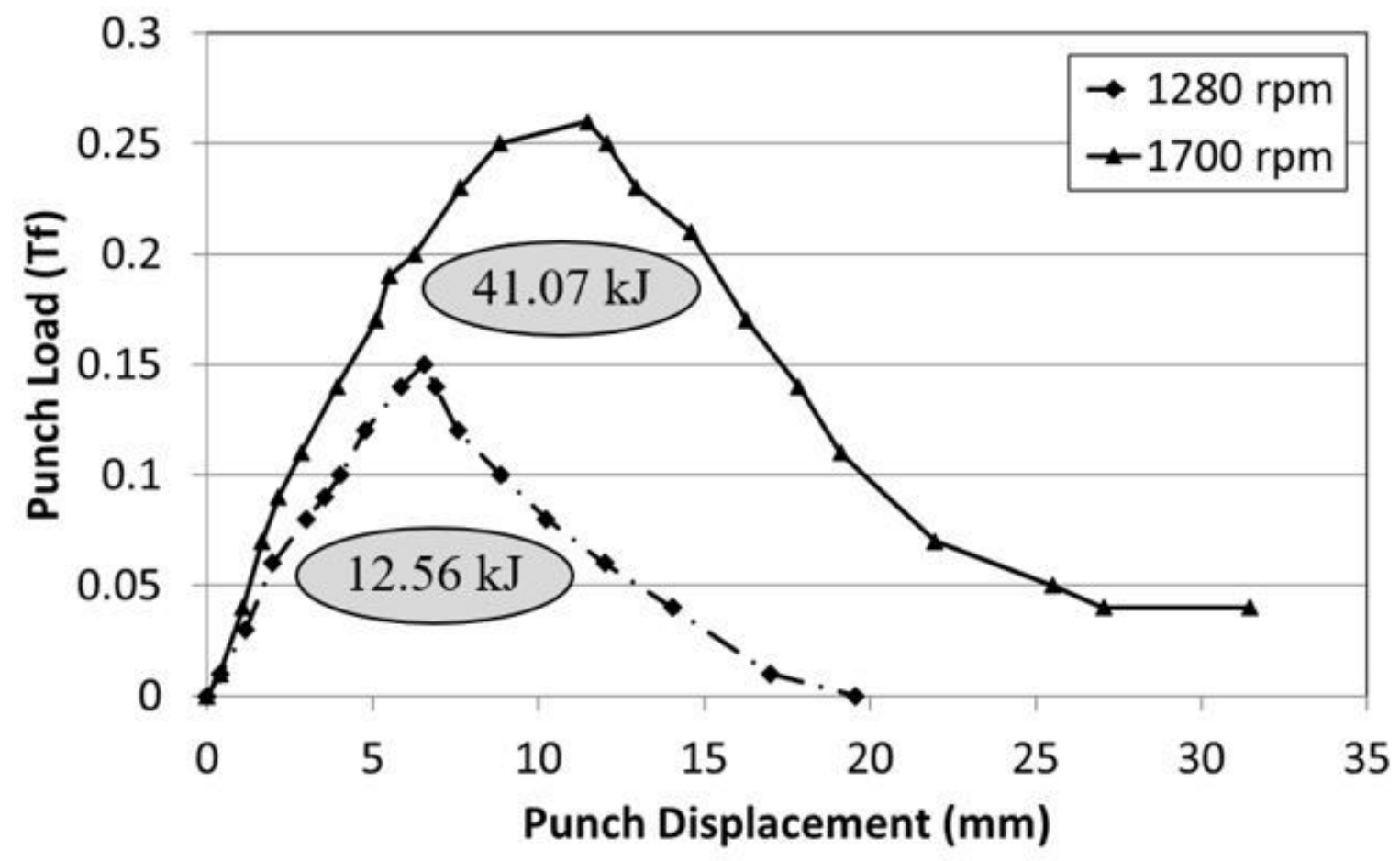

Figure 6

Bending load-displacement curve for the Al-Cu joint welded at rotational speeds of $1700 \mathrm{rpm}$ and 1280 $\mathrm{rpm}$, while the traverse speed was constant at $16 \mathrm{~mm} / \mathrm{min}$. The copper has been annealed.

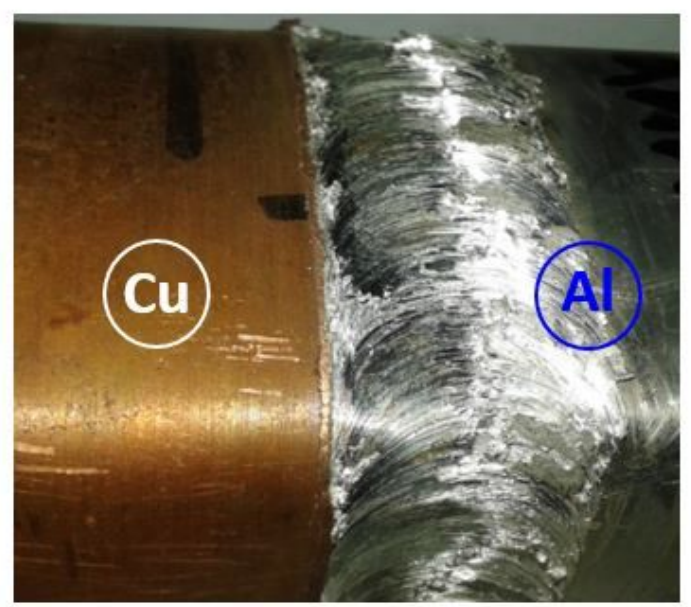

(a) $1700 \mathrm{rpm}$

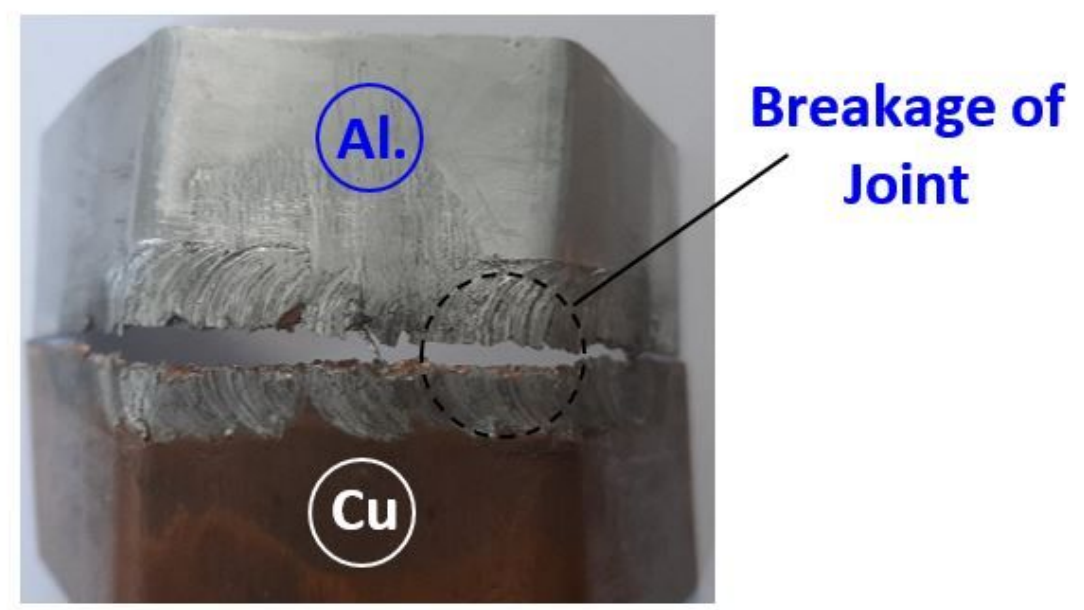

(b) $910 \mathrm{rpm}$

Figure 7 
Images of the Al-Cu joint welded at rotational speeds of (a) $1700 \mathrm{rpm}$ and (b) $910 \mathrm{rpm}$ after the bending test. The traverse speed is equal to $16 \mathrm{~mm} / \mathrm{min}$. The copper has been annealed.

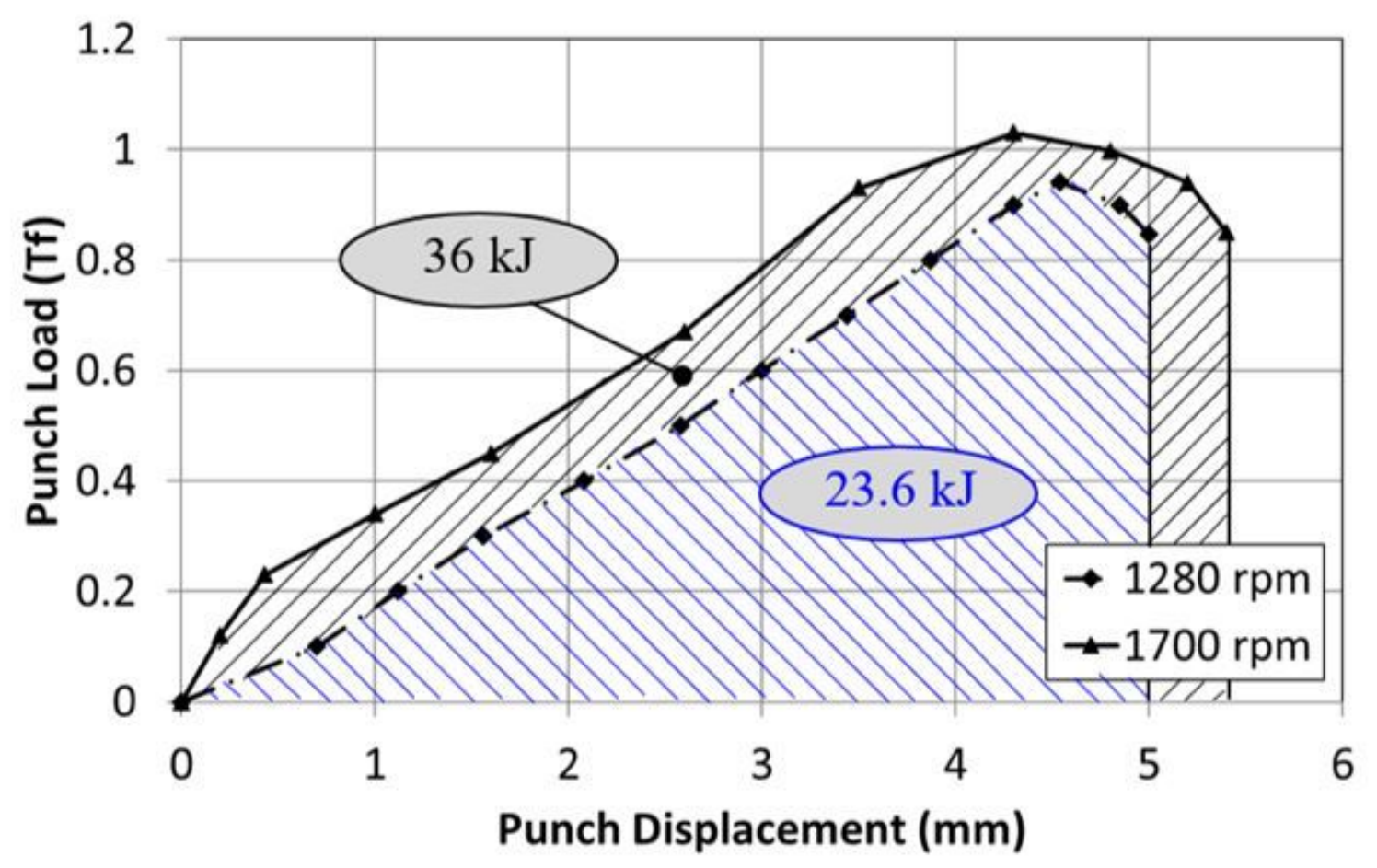

Figure 8

Cup load-displacement curve for the Al-Cu joint welded at rotational speeds of $1700 \mathrm{rpm}$ and $1280 \mathrm{rpm}$, while the traverse speed was constant at $16 \mathrm{~mm} / \mathrm{min}$. The copper has been annealed.
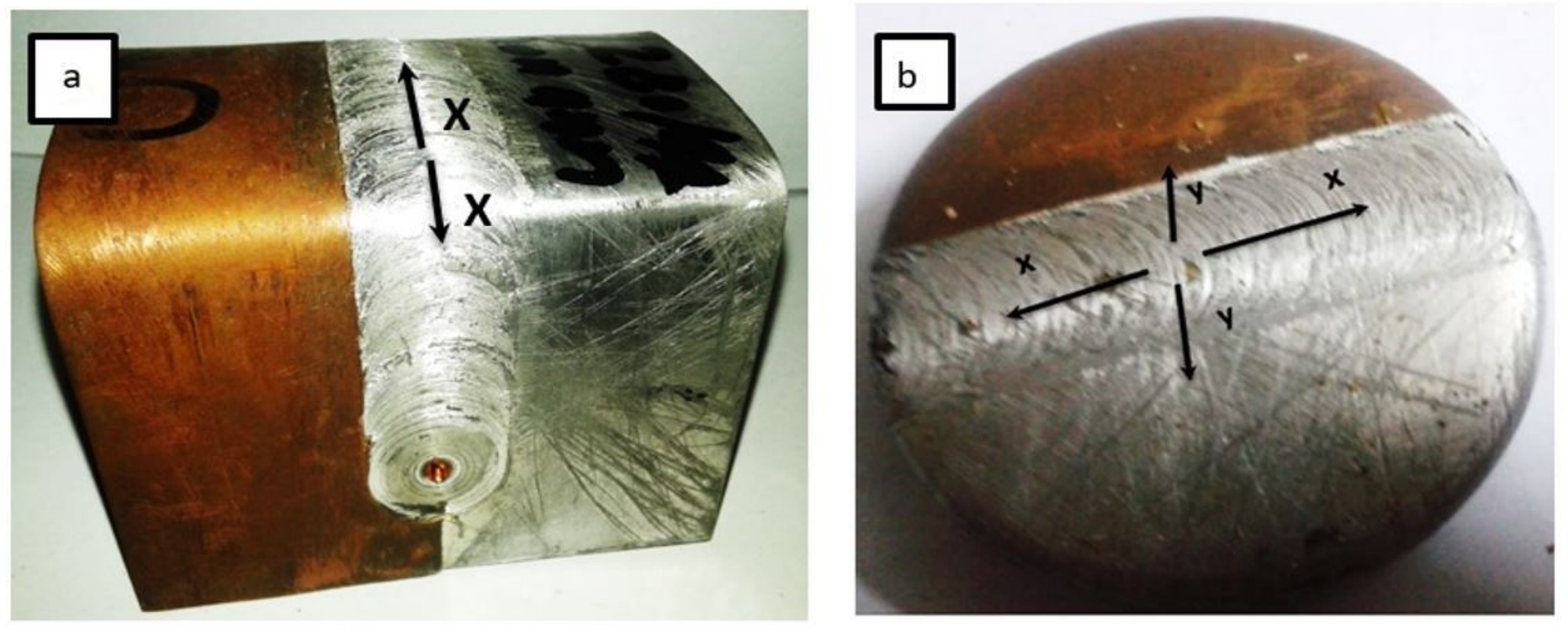

Figure 9 
forming force direction in: (a) bending test, and (b) cup-forming test. x-direction is the direction parallel to the welding line, while the $y$-direction is the direction perpendicular the welding line.

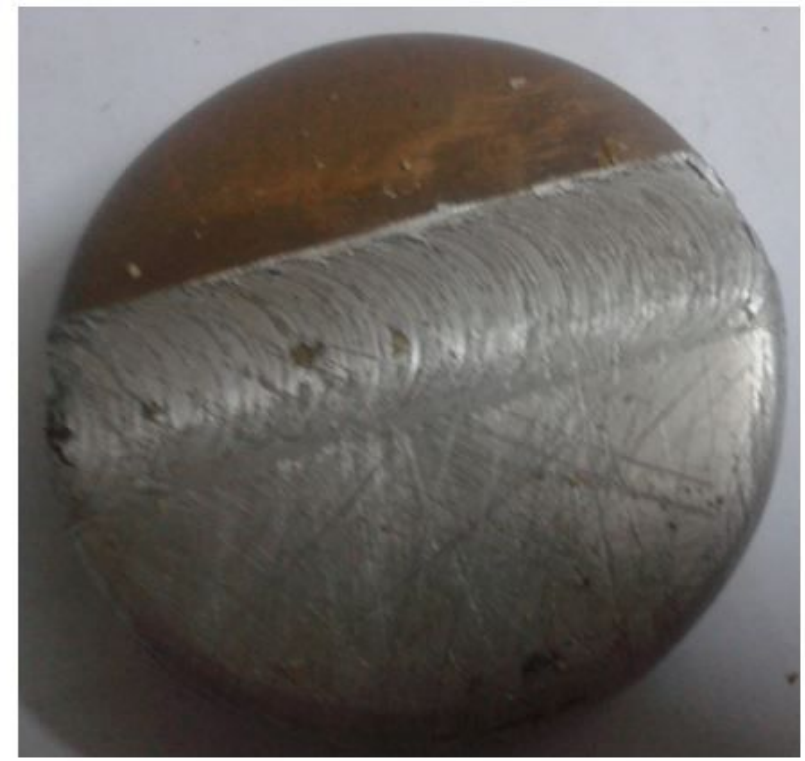

(a) $1700 \mathrm{rpm}$

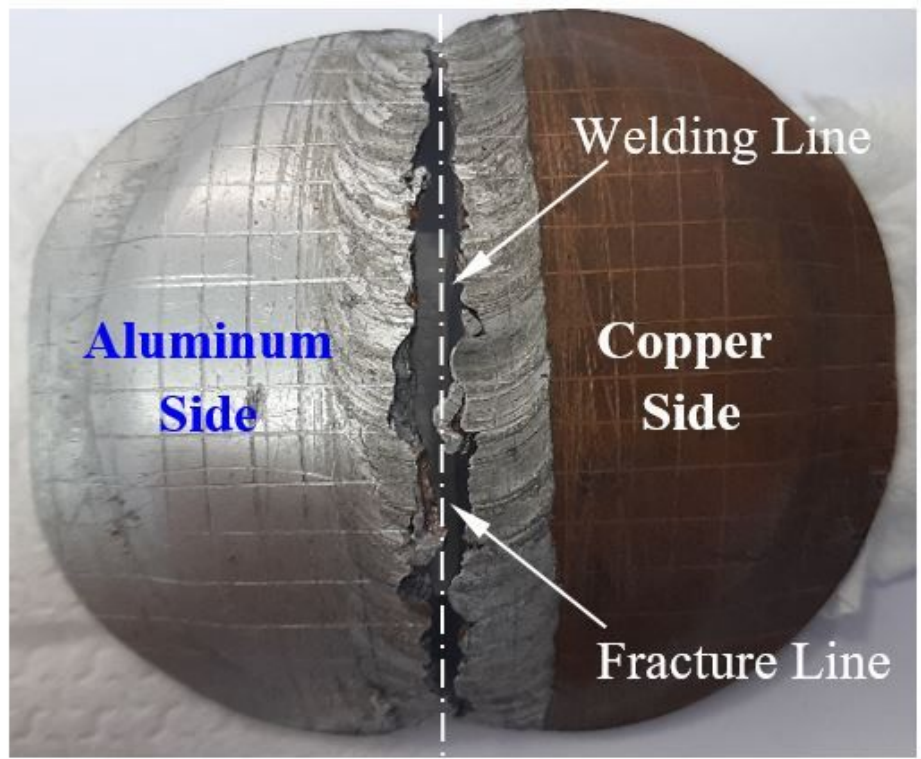

(b) $910 \mathrm{rpm}$

\section{Figure 10}

Images of the Al-Cu joint after the cup test, and that in case of welding at rotational speeds of (a) 1700 rpm and (b) $910 \mathrm{rpm}$. The traverse speed is equal to $16 \mathrm{~mm} / \mathrm{min}$. The copper has been annealed. 


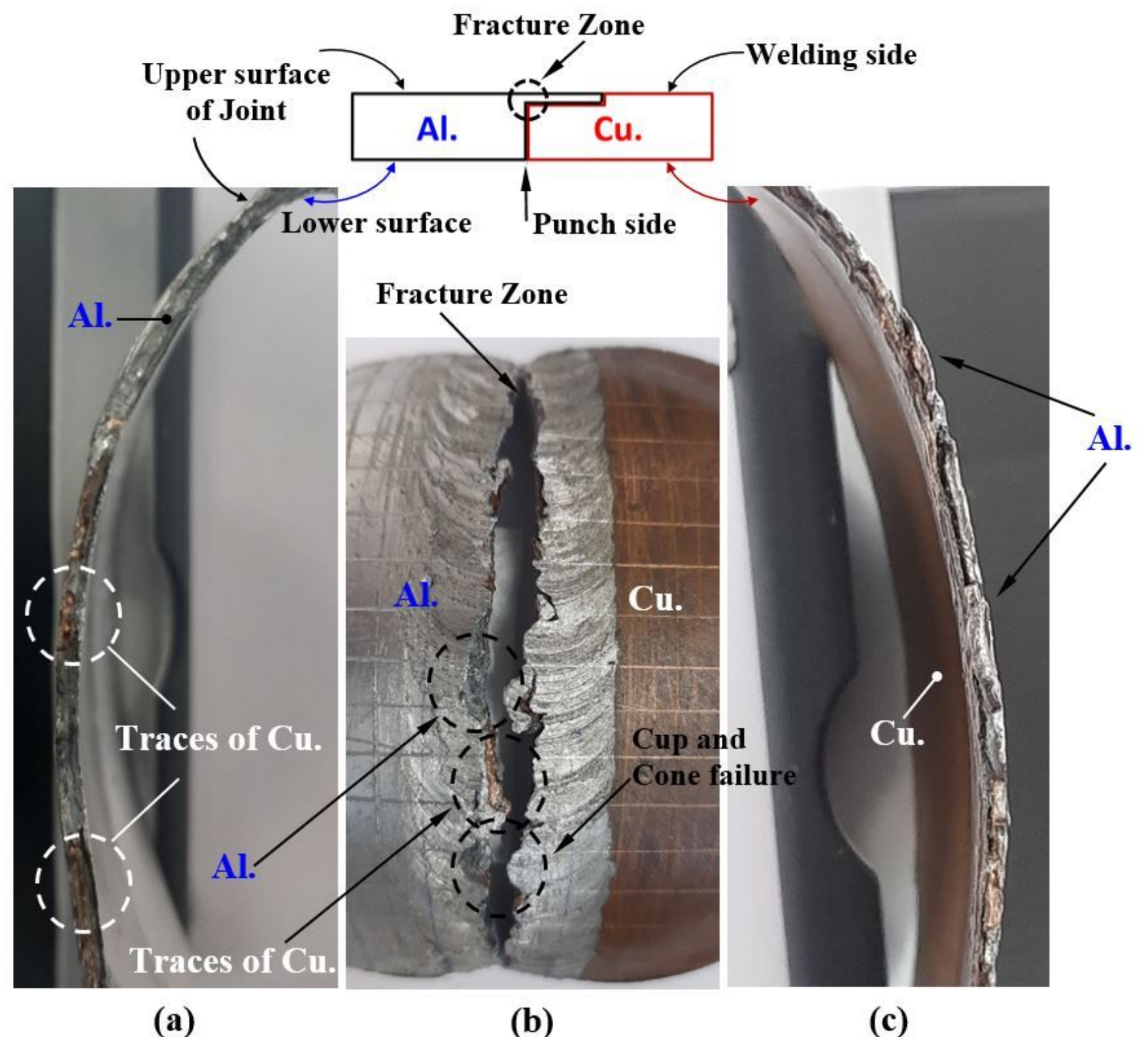

Figure 11

Image of the fractured Al-Cu joint after the cup test, where (a) is a cross section of the fracture zone at the Aluminum side, (b) is Al-Cu joint after fracture and (c) is a cross section of the fracture zone at the copper side. The Al-Cu joint is welded at a rotational speeds of $910 \mathrm{rpm}$ and traverse speed of $16 \mathrm{~mm} / \mathrm{min}$. The copper has been annealed. 


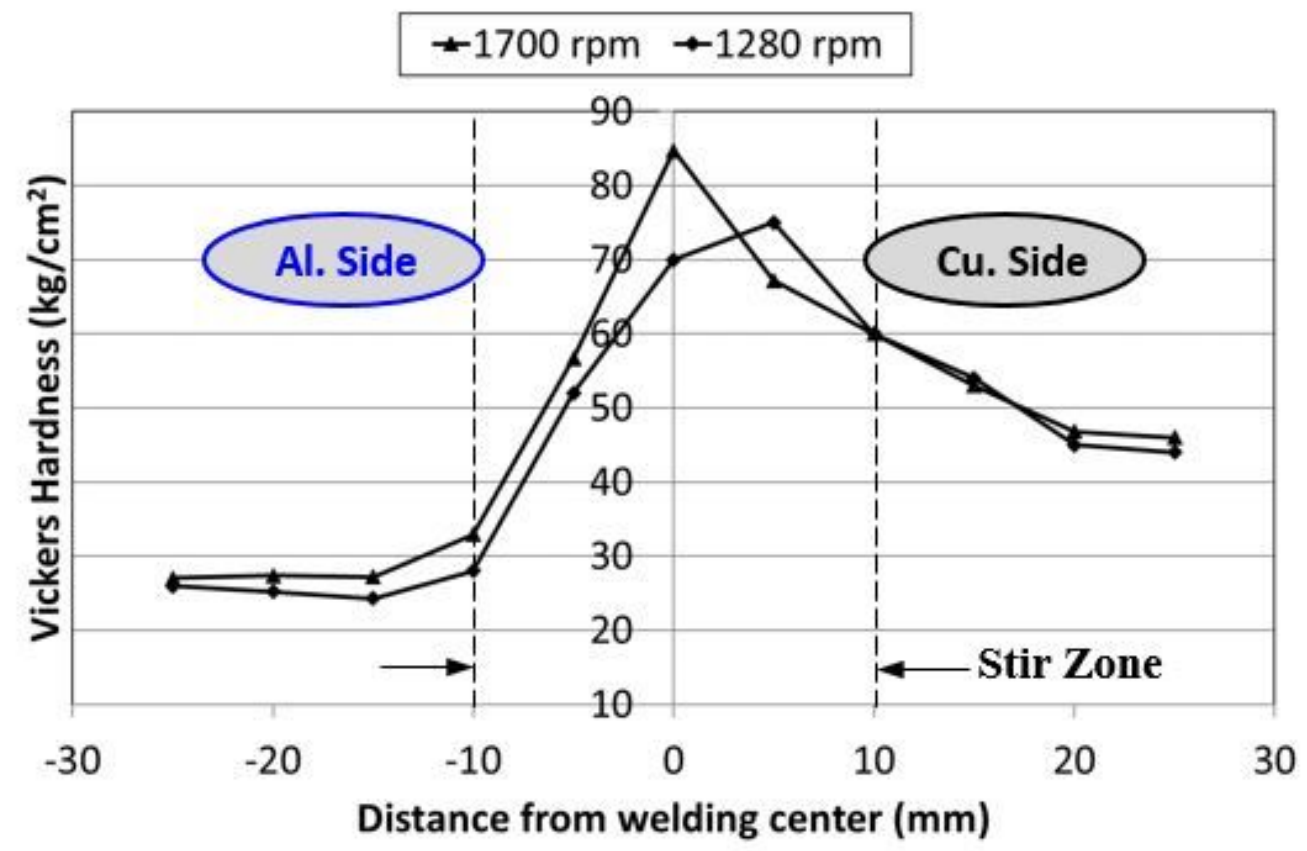

(a)

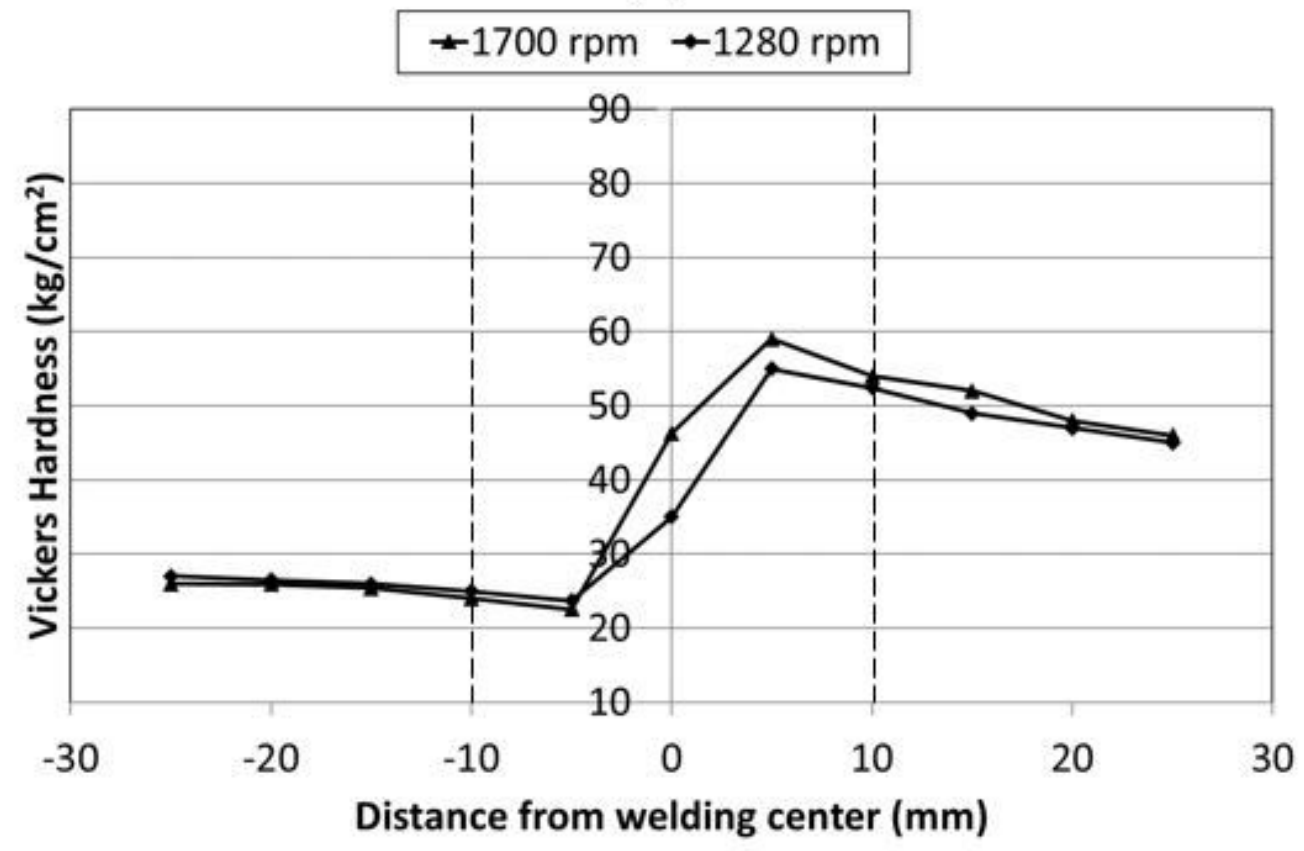

(b)

Figure 12

Micro-Hardness distribution at (a) the top and (b) the bottom surface of the Al-Cu welded joint. The Al-Cu joint is welded at rotational speeds of $1700 \mathrm{rpm}$ and $1280 \mathrm{rpm}$, while the traverse speed was constant at $16 \mathrm{~mm} / \mathrm{min}$. The copper has been annealed. 